\title{
Mahamoud Darwich, Palestino e Pele-Vermelha
}

Laymert Garcia dos Santos ${ }^{1}$

\begin{abstract}
Resumo: Este ensaio trata da atualidade da obra do poeta palestino Mahamoud Darwich, especialmente para o contexto de desespero e de tragédia presente no Brasil. Darwich extrai do passado os acontecimentos que seguem ressoando no presente e vê com clareza como a condição agonizante do Palestino sobrepõe-se à do Índio, mais precisamente Pele-Vermelha. É como poeta, como homem que busca a fonte da poesia no continuum da relação cósmica, mítica, com a natureza, que ele se vê na pele vermelha. Mais do que através de uma abstrata noção de pátria, a relação justaposta Pele-Vermelha = Palestino se desenha como intensidade de parentesco com a natureza e seu caráter cósmico, através da Terra, tecendo, assim, uma relação essencial para as nossas futuras gerações apreenderem a paixão de um povo pelo seu lugar no mundo.
\end{abstract}

Palavras-chave: Mahamoud Darwich, Pele-Vermelha, Terra, Palestino, Brasil.

\section{MAHAMOUD DARWICH, PALESTINE AND REDSKIN}

\begin{abstract}
This essay discusses the relevance of the Palestinian poet Mahamoud Darwich's work, especially in the context of despair and tragedy present in Brazil. Darwich extracts, in the past, the events that keep resonating in the present and sees clearly how the agonizing condition of the Palestinian overlaps with that of the Indian, more precisely Redskin's. It is as a poet, as a man who seeks the source of poetry in the continuum of the cosmic,
\end{abstract}

1 Professor Titular do Departamento de Sociologia do Instituto de Filosofia e Ciências Humanas da Universidade Estadual de Campinas (Unicamp). 


\begin{abstract}
mythical relationship with nature, that he sees himself in red skin. More than through an abstract notion of homeland, the juxtaposed relationship Redskin $=$ Palestinian is drawn as an intensity of kinship with nature, and its cosmic character, across the Earth, thus weaving an essential relationship for our future generations to grasp the passion of a people for its place in the world.
\end{abstract}

Keywords: Mahamoud Darwich, Redskin, Earth, Palestinian, Brazil.

No momento em que se inaugura a Exilium: Revista de Estudos da Contemporaneidade, vinculada à Cátedra Edward Saïd, da Pró-Reitoria de Pós-Graduação e Pesquisa da Universidade Federal de São Paulo, creio não haver nada mais oportuno do que evocar Mahamoud Darwich. Vivemos sob um governo de ultradireita cuja estratégia compreende, entre outros, dois temas cruciais que, interligados, tornam atualíssima, quiçá imprescindível, a leitura de sua obra. Pois, com o bolsonarismo, estamos presenciando o ataque aberto aos povos indígenas e a adoção de uma política destrutiva com a terra, o lugar e o meio (veneno dos agrotóxicos nas plantações; desmatamento acelerado; mercúrio do garimpo nos rios; descaso com a poluição dos mares; lama de barragem rompida; desmantelamento das instituições de fiscalização e controle...) que merecem ser considerados à luz de seus escritos. Se percebermos as conexões entre tais temas e as questões que neles ressoam através da vida e da poesia do poeta máximo da Palestina, talvez possamos aprender com os palestinos a lidar com o nosso momento, isto é, com o desespero, o exílio e a tragédia concebidos a partir de uma perspectiva vital.

São muitas as possíveis portas de entrada para a poesia e para a vida de Darwich. Como as nossas experiências de vida parecem ser muito distantes das dele e dos Palestinos, escolho a que me parece mais próxima, a de maior ressonância. Aquela em que o poeta palestino se descobre índio na própria condição de poeta e de Palestino. Mais precisamente, Pele-Vermelha.

Preso duas vezes pelos israelenses por razões políticas em sua juventude, Darwich se viu como um espectro assombrando seus algozes. Em Présente absence [Presente ausência], sua última autobiografia poética publicada em 2006 , dois anos antes de sua morte, o poeta escreve: 
Espectro que leva o guarda a vigiar. Chá e um fuzil. Quando o vigia cochila, o chá esfria, o fuzil cai de suas mãos e o Pele-Vermelha infiltrase na história

A história é que és um Pele-Vermelha

Vermelha de plumas, não de sangue. És o pesadelo do vigia

Vigia que caça a ausência e massageia os músculos da eternidade

A eternidade pertence ao guarda. Bem imobiliário e investimento. Se necessário, ele se torna um soldado disciplinado em uma guerra sem armistício. E sem paz

Paz sobre ti, no dia em que nascestes e no dia em que ressuscitarás na folhagem de uma árvore

A árvore é um agradecimento erguido pela terra como uma confiança em seu vizinho, o céu [...] $]^{2}$

"A história é que és um Pele-Vermelha". No início dos anos 1990, em "Na última noite, nesta terra", Darwich havia publicado o "Discurso do homem vermelho", no qual abordava a problemática do Outro. Para escrevê-lo, havia lido uma vintena de livros sobre a história dos PeleVermelha e a literatura deles. Queria impregnar-se de seus textos, dos discursos dos chefes. Precisava conhecer suas roupas, os nomes de suas aldeias, a flora, os modos de vida, o ambiente, os instrumentos, as armas, os meios de transporte. Ora, por que esse interesse tão agudo nos povos indígenas norte-americanos, tão distantes no espaço e no tempo, aparentemente tão sem conexão com o que se passava na Palestina na segunda metade do século $X X$ ?

No material coletado para escrever seu "Discurso...", Darwich inspirou-se particularmente na fala do cacique Seattle no Congresso norte-americano, em 1854, em resposta à proposta formulada por Isaac Stevens, governador do Território de Washington, de comprar as terras indígenas. Ali, o líder indígena dizia:

Cada parcela deste solo é sagrada na avaliação de meu povo. Cada encosta, cada vale, cada planície e arvoredo foram consagrados por algum acontecimento triste ou feliz nos dias que há tempos desvaneceram. Até as pedras, que parecem ser mudas e mortas

2 DARWICH, M. Présente absence. Tradução do árabe Farouk Mardam-Bey e Elias Sanbar. Arles: Actes Sud, 2016. p. 146-147. (Col. Mondes arabes). 
como o calor sufocante do sol na praia silente, estremecem com as memórias de comoventes acontecimentos conectados com as vidas do meu povo, e até o pó sobre o qual agora erguei-vos responde mais amorosamente aos pés dele do que aos vossos, porque é rico com o sangue dos nossos ancestrais, e os nossos pés descalços são conscientes do toque empático. Nossos bravos falecidos, queridas mães, alegres e amorosas esposas, e até mesmo as criancinhas que viveram aqui e aqui se alegraram durante uma breve estação, amarão essas solidões sombrias e a cada entardecer saúdam os espíritos das sombras que retornam. E quando o último Pele-Vermelha desaparecer, e a memória de minha tribo se tornar um mito entre os Homens Brancos, estas praias fervilharão com os mortos invisíveis da minha tribo ${ }^{3}$.

Ora, a relação sagrada com a terra e com o lugar é a mesma que encontramos no "Discurso do homem vermelho". Vejamos este trecho:

Assim, somos o que somos no Mississipi. E cabem a nós as relíquias de ontem. Mas a cor do céu mudou e, a Leste, o mar mudou. Ô senhor dos Brancos, domador dos cavalos, o que esperas dos que partem com as árvores da noite? Elevada é nossa alma e sagradas são as pastagens. $E$ as estrelas são palavras que iluminam. Escruta-as e lerás nossa história inteira: aqui nascemos entre fogo e água, e logo renasceremos nas nuvens às margens do litoral azulado. Não firas ainda mais a relva, ela possui uma alma que defende em nós a alma da terra. Ô domador dos cavalos, domestica tua montaria, que ela diga à alma da natureza seu pesar pelo que fizestes com as nossas árvores. Árvore minha irmã. Eles te fizeram sofrer, como a mim. Não peças misericórdia para o lenhador da minha mãe e da tua [...].

Há mortos que cochilam nos quartos que erguereis. Mortos que visitam o seu passado nos lugares que demolireis. Mortos que cruzam as pontes que construireis. E há mortos que iluminam a noite das borboletas que chegam à aurora para tomar chá convosco, calmas como os vossos fuzis que as abandonaram. Deixai, então, ô convidados do lugar, alguns

3 SMITH, Henry A. Chief Seattle's 1854 Speech. Center for the Study of the Pacific Northwest. Disponivel em: https://www.washington.edu/uwired/outreach/cspn/ Website/Classroom $\% 20$ Materials/Reading\%20the\%20Region/Texts $\% 20$ by $\% 20$ and\%20about\%20Natives/Texts/7.html. Acesso em: 1 ago. 2020. 
assentos livres para os anfitriões, que eles vos leiam as condições da paz com os defuntos ${ }^{4}$.

A boca do Pele-Vermelha, porém, porta a voz do chefe índio e a do Palestino. Mais do que através de uma abstrata noção de pátria, a relação Pele-Vermelha $=$ Palestino se desenha como intensidade de parentesco com o lugar, com a natureza e seu caráter cósmico. Como o cacique, o poeta palestino pertence à terra; e não a terra a ele. Assim, a carga poética da enunciação é a mesma nos dois discursos e expressa a solenidade da locução, seu caráter sagrado, transcendente. No entanto, ao mesmo tempo, os dois discursos se pretendem históricos, fazem História, são marcos de acontecimentos tremendos.

Escrevendo o "Discurso do homem vermelho", Darwich levantou a questão do genocídio indígena nas Américas e da relação que ele tinha com o fim da presença árabe na Península Ibérica. Tratava-se de estabelecer o sentido da imposição do Ocidente e de sua cosmovisão. Com efeito, em entrevista a Subhi Hadidi e Basheer al-Baker, o poeta esclarece o motivo estético e político dessa incursão na História:

Distingo entre a crônica e o arquivo. Meus poemas dizem o direito, a recusa de que a força imponha seus "direitos". Podem objetar-me que a História não passa de uma longa sucessão desses direitos nascidos do uso da força. Isso significa que o fraco é obrigado a aceitar sua ausência forçada e até a colaborar com o seu próprio desaparecimento? Pelo contrário, não deve ele continuar combatendo para permanecer presente? O registro histórico sobre o qual trabalho é aquele da defesa do direito, ainda que me digam que é pela espada que nascem os Estados. A poesia não pode conciliar-se com a força, pois ela é habitada pelo dever de criar sua própria força, fundando um espaço vital para a defesa do direito, da justiça e da vítima. A poesia é a aliada indefectível da vítima e só pode encontrar terreno de entendimento com a História com base nesse princípio fundamental. É sob esse ângulo que precisamos compreender a temática dos Pele-Vermelha ou da queda de Granada para propor, em 1992, uma leitura humanista de 1492.

4 DARWICH, M. Discours de l'indien rouge. Tradução para o francês de Elias Sandar. Culture et politique arabes, $14 \mathrm{fev}$. 2010. Disponível em: https://cpa.hypotheses. org/1641. Acesso em: 1 ago. 2020. 
Naquele ano, o mundo ocidental atrelou-se à interpretação do alcance histórico de 1492 e, mais particularmente, de dois episódios fundadores para o Ocidente: a viagem de Colombo e a queda de Granada. O primeiro dos dois acontecimentos foi uma conquista acompanhada de um projeto genocida, na linhagem do espírito das guerras cruzadas. 0 segundo consagrou definitivamente a ideia de Ocidente e expulsou os árabes do caminho que levava a esse mesmo Ocidente.

Sou um cidadão do mundo que eles destruíram ou chutaram para fora da História. E sou uma vítima cujo único bem é a autodefesa. Mergulhei em uma leitura aprofundada da história dos árabes na Espanha e dos índios e sua relação com a terra, os deuses e o Outro. 0 que me impressionou nos índios é que eles apreenderam os acontecimentos como manifestações de um destino incontornável e os enfrentaram com o espanto daqueles que veem a história geral se abater sobre a "história privada". A consagração do conceito de Ocidente exigiu o desaparecimento de 70 milhões de seres humanos, bem como uma guerra cultural furiosa contra uma filosofia intrinsecamente mesclada à terra e à natureza, às árvores, às pedras, à turfa e à água. 0 homem vermelho desculpava-se, com ardor de surpreendente poesia, da árvore que ia cortar, explicando a necessidade vital da sua casca, do seu tronco, dos seus ramos; em seguida, lançava um pedaço de tronco na floresta para que a árvore renascesse... A máquina venceu essa santidade que o homem vermelho atribuía à sua terra, uma terra divinizada, pois não distinguia entre as suas fronteiras e as dos deuses.

Coloquei-me na pele do índio para defender a inocência das coisas, a infância da humanidade; para alertar contra a máquina militar tentacular que não vê limites para o seu horizonte, mas arranca todos os valores herdados e devora, insaciável, a terra e as suas entranhas. [...] Meu poema tentou encarnar o Pele-Vermelha no momento em que ele olhou o derradeiro sol. Mas o "branco" não encontrará mais repouso nem sono, pois as almas das coisas, da natureza, das vítimas ainda volteiam sobre sua cabeça ${ }^{5}$.

Darwich extrai, assim, no passado, os acontecimentos que seguem ressoando no presente e vê com clareza como a condição agonizante do Palestino sobrepõe-se à do Índio. Mas não é só a privação derradeira, a privação do direito de recusar uma vida e um estatuto abomináveis que o

5 DARWICH, M. La Palestine comme métaphore. Tradução do árabe Elias Sanbar; tradução do hebraico Simone Bitton. Arles: Actes Sud, 1997. p. 78-80. (Col. Babel). 
levam ao encontro do Índio; é preciso assinalar que é como poeta, como homem que busca a fonte da poesia no continuum da relação cósmica, mítica, com a natureza, que Darwich se vê na pele vermelha. O PeleVermelha infiltra-se na História como o selvagem resiste na "civilização" - ser poeta-índio e índio-poeta, ao mesmo tempo, é assumir uma condição ontológica e epistemológica.

Mas é, também, ser um mistanenim, o Palestino-Árabe infiltrado em território ocupado e no pesadelo israelo-americano. E é aqui que a dimensão política da ressonância Pele-Vermelha-Palestino se explicita. Encontramos a chave dessa explicitação em Être árabe [Ser árabe], livro de entrevistas de Christophe Kantcheff com Farouk Mardam-Bey e Elias Sanbar, dois amigos próximos de Darwich, tradutores de vários dos seus livros para o francês e companheiros no seu longo exílio em Paris. Da mesma forma que o poeta, Sanbar foi e é um intelectual palestino que atuou como verdadeiro diplomata na Europa, defendendo a causa palestina nos campos da política, das ideias e da cultura. Da mesma forma que o poeta, Sanbar também pertencia à Organização de Libertação da Palestina (OLP).

A Palestina, observa Elias Sanbar, é uma nação sem Estado. Como pode, então, existir um sentimento nacional tão vivo, tão forte? Segundo ele, isso ocorre em virtude da centralidade da questão do lugar. Desde o início, no entender de Sanbar, tratou-se de uma substituição e não apenas de uma ocupação, nem de uma exploração colonial, nem de uma colonização clássica. Desde a Declaração Balfour, de 2 de novembro de 1917, o projeto sionista consistiu na volatilização de uma terra árabe e na sua substituição por uma outra. Portanto, diz Sanbar:

[...] os Palestinos serão submetidos a uma ofensiva de domínio dos lugares, um domínio no qual a apropriação da terra, que, embora semelhante como duas gotas d'água a uma aquisição clássica, comum, de uma propriedade por uma pessoa privada ou uma pessoa moral no caso, o "povo judeu" representado pela Agência judaica -, será na realidade apenas um elemento, importante, claro, mas um elemento de um edifício visando não a constituição de uma imensa propriedade de 26320 quilômetros quadrados, isto é, a superfície da Palestina, mas o desaparecimento de um país ${ }^{6}$.

6 MARDAM-BEY, F.; SANBAR, E. Être árabe: Entretiens avec Christofe Kantcheff. Arles: Actes Sud, 2005. p. 74-75. (Col. Sindbad). 
Um país, quer dizer, um espaço considerado por séculos pelos Palestinos como a sua terra natal. Por isso mesmo, os filhos da terra, embora se considerassem Árabes e falassem árabe, se diziam "Árabes da Palestina". Esse duplo pertencimento é constitutivo dos seus seres. Por sua vez, como para confirmar essa condição, todos os Árabes de outros países "verão no projeto anglo-sionista uma ofensiva contra um membro, no sentido fisiológico, de seu corpo. E como a própria posição da Palestina nos mapas ajuda, esta se verá espontaneamente assimilada como o mais vital dos órgãos, 'o coração dos Árabes'"'?.

Com efeito, em novembro de 1917 o povo palestino fica sabendo que o ministro inglês James Balfour prometera seu país a um movimento vindo do Ocidente, comprometido com a ideia de promover o retorno dos judeus após um exílio de dois mil anos e de restaurar um "Estado dos judeus" na Palestina. Tem início, então, o conflito. Os Palestinos reagem imediatamente ao texto de Balfour. Mas, perplexos, caem em uma armadilha, pois aceitam os termos da declaração que os designam como "comunidades não judaicas na Palestina". Assim, com Balfour, não só o "povo judeu" "volta" a um antigo território que haveria sido seu, como encontra ali não uma nação e um povo, mas "comunidades não judaicas", isto é, de outra religião, muçulmana e cristã. Desse modo, desmonta-se a identidade palestina secular. E isso tem como corolário o fato de que os Palestinos judeus não só deixam de existir como parecem nunca ter existido!

Doravante - continua Elias Sanbar -, tudo se passa entre o povo judeu que retorna e duas outras comunidades que esperam partir para ceder lugar, o seu lugar. A história contemporânea da Palestina reduzirse-á, então, sob diversas formas, a uma repetição permanente de um enunciado terrível: os Palestinos se encontram permanentemente em instância de ausência anunciada ${ }^{8}$.

De nada adianta cristãos e muçulmanos reivindicarem o estatuto de "povo da Palestina" e afirmarem que já estavam lá antes dos judeus. Tampouco adianta afırmarem sua presença no lugar - os sionistas

7 Ibidem, p. 78.

8 MARDAM-BEY, F.; SANBAR, E. Être árabe: Entretiens avec Christofe Kantcheff. Arles: Actes Sud, 2005. p. 82. (Col. Sindbad). 
argumentam que, na verdade, a Palestina é um território vazio, um deserto, segundo a famosa frase de Israel Zangwill: "O sionismo é um povo sem terra que volta a uma terra sem povo".

Conhecemos bem esse tipo de argumento, que também foi usado no Brasil da ditadura para justificar o projeto "desenvolvimentista" de "ocupação" e de "integração" da Amazônia, desconhecendo deliberadamente que ela era e é habitada por povos indígenas, a quem também os militares brasileiros negam o direito ao emprego do termo "povos", visto que povo, nessas paragens, só existiria um, o brasileiro. Mas voltando à Palestina: cria-se uma diferença absoluta entre a vivência do colono israelense e a do cidadão palestino: o primeiro pensa que esteve lá há milênios e, por isso, pode voltar; o segundo sabe que nunca partiu, que tem o direito de viver ali... porque é dali!

Assim, desde o início do século $\mathrm{XX}$, o projeto de constituição do Estado de Israel já preconiza a expulsão do povo palestino e institui a sua condição de refugiado ou de exilado em sua própria terra. Por isso, Sanbar afırma: "O que marca e marcará profundamente o ser palestino é que cedo essa sociedade sabe que está engajada em um combate que ultrapassa a independência que ela reivindica. Ela luta para continuar a existir no lugar, no seu lugar"'.

Ora, como bem sublinha Elias Sanbar, Israel nasce da mesma maneira que nasceram os Estados Unidos - os sionistas repetem a mesma lógica adotada pelos colonizadores na América: aos Palestinos caberá, então, o destino de se transformarem em Pele-Vermelha, isto é, autóctones destinados à ausência. Como os Índios, os Palestinos ficam sem lugar.

Ao longo de todo o século XX, a questão, no fundo, sempre foi a mesma. De um lado, uma guerra de conquista do território, uma guerra de ocupação progressiva e de negação da existência do autóctone; de outro, resistência e afirmação obstinada de existência do homem e do lugar. Não cabe aqui nos determos nas datas-chave desse conflito que, oficialmente, explode em 1948 com a criação do Estado de Israel e o desaparecimento da Palestina do mapa e dos dicionários enquanto país. Desde então, a determinação israelense de fazer país e povo sumirem prolonga-se na

$9 \quad$ Ibidem, p. 92 
Guerra dos Seis Dias, em 1967, estende-se na invasão do Líbano no início dos anos 1980, com o Massacre de Sabra e Chatila, ganha novos contornos com a Intifada e, posteriormente, com as intermináveis negociações de paz que nunca põem um fim ao avanço sistemático da colonização dos territórios ocupados...

Mas se há semelhança de destino entre os Pele-Vermelha e os Palestinos, também há diferença e ela precisa ser registrada. Em uma conversa entre Elias Sanbar e Gilles Deleuze, publicada pelo jornal Libération, em 8-9 de maio de 1982, o filósofo francês aborda o assunto:

Muitos artigos da Revue d'études Palestiniennes lembram e analisam de maneira nova os procedimentos pelos quais os Palestinos foram expulsos de seus territórios. Isso é muito importante porque os Palestinos não se encontram na situação de gente colonizada, mas sim evacuada, expulsa. [...] É que há dois movimentos muito diferentes no capitalismo. Ora trata-se de manter um povo em seu território e de fazê-lo trabalhar, de explorá-lo, para acumular um excedente - é o que comumente se chama colônia. Ora, pelo contrário, trata-se de esvaziar um território de seu povo para dar um salto adiante, trazendo mão de obra de outras partes. A história do sionismo e de Israel, como a da América, passou por isso: como criar o vazio, como esvaziar um povo? ${ }^{10}$

Até aí, estamos ainda no campo da semelhança. Mas, segundo Deleuze, quem demarcou o limite da comparação foi Yasser Arafat ao apontar que existe um mundo árabe enquanto os Pele-Vermelha não dispunham de nenhuma base ou força fora do território do qual eram expulsos. Sanbar concorda com essa análise: "Somos expulsos singulares porque não fomos deslocados para terras estrangeiras, mas para o prolongamento de nossa 'casa'. Fomos deslocados em terra árabe, onde não só ninguém quer nos dissolver, mas essa própria ideia é uma aberração"11.

Assim, os Palestinos não foram confınados em "reservas", como os Pele-Vermelha. Deslocados "dentro de casa", para o meio de povos irmãos

10 DELEUZE, G. Deux régimes de fous: textes et entretiens 1975-1995. Paris: Les Éditions de Minuit, 2003. p. 180-181.

11 Ibidem, p. 181. 
e solidários, os Palestinos assumiram a condição do exílio de um modo muito particular. Como aponta Sanbar, todo exílio comporta duas rupturas: uma com o lugar de partida, outra com o lugar de chegada. Ele diz:

Ora, expulsos e forçados a se deslocar, os Palestinos continuavam sendo Árabes e em momento algum seu deslocamento suscitará uma diáspora, pois esta exige que se eleja residência em uma terra estrangeira. 0 que precisamente não eram os países vizinhos que os acolheram. Os Palestinos se encontravam refugiados, é claro, mas em sua continuidade territorial e identitária; deslocados, é claro, mas dentro de sua língua, sua cultura, sua cozinha, sua música, seu imaginário. Mais ainda: compartilhavam com os povos que os acolhiam o sonho da unidade em um grande Estado árabe ${ }^{12}$.

Nesse sentido, "[...] os refugiados reagem como homens e mulheres/ território, isto é, estão convencidos de transportar com eles, neles, sua terra, esperando efetuar o Retorno e 'repousá-la em seu lugar'"'13. É essa condição complexa e trágica que faz Mahamoud Darwich, trinta anos depois de deixar a Palestina, se encontrar em Gaza e escrever: "Vim, mas não cheguei. / Estou aqui, mas não voltei!".

Com efeito, não se pode voltar de onde nunca se saiu, porque nunca se abandonou o lugar. Por isso, importa agora salientar que Darwich foi a voz que enunciou, com todas as letras, todas as camadas de sentido dessa complexa condição. Não foi à toa que se tornou um patrimônio coletivo do povo palestino, que o vê como o seu porta-voz. Chegou ao ponto de escrever um comovente poema para a sua mãe e todos os leitores/ouvintes lerem/ouvirem naquele termo a palavra Palestina. É impressionante: percorrer a obra de Darwich é perceber que ele é Palestino, é Árabe, é o refugiado, é o exilado de dentro e o exilado de fora, é o infiltrado, é o Pele-Vermelha; é, também, o Troiano vencido que nenhum Homero cantou e o Cananeu cuja Bíblia se perdeu. Darwich é tudo isso porque é poeta que acessa diretamente a potência da matriz ancestral da poesia - a presente ausência de onde ela brota.

\footnotetext{
12 DELEUZE, G. Deux régimes de fous: textes et entretiens 1975-1995. Paris: Les Éditions de Minuit, 2003. p. 166.

13 Ibidem, p. 166-167.
} 
Não te perguntas mais: 0 que escrever? mas: Como escrever? Invocas um sonho. Ele foge da imagem. Solicitas um sentido. A cadência se torna estreita para ele. Crês que ultrapassastes o limiar que separa o horizonte do abismo, que te exercitastes a abrir a metáfora para uma ausência que se torna presença, para uma presença que se ausenta com uma espontaneidade de aparência dócil. Sabes que em poesia o sentido é movimento em uma cadência. Nela a prosa aspira ao pastoral da poesia, e a poesia à aristocracia da prosa. Leva-me ao que não conheço dos atributos do rio... Leva-me. Uma linha melódica semelhante a esta abre seu caminho no curso das palavras, feto em devir que traça os traços de uma voz e a promessa de um poema. Mas ela precisa de um pensamento que a guie e que ela guia através das possibilidades, de uma terra que a porta, de uma inquietação existencial, de uma história ou de uma lenda. 0 primeiro verso é o que os perplexos nomearam, segundo sua origem, inspiração ou iluminação ${ }^{14}$.

É espantosa para nós, brasileiros, a determinação com que os palestinos se aferram à sua identidade, à sua língua e ao seu lugar. Para nós, é quase incompreensível. Daí a importância de Mahamoud Darwich como emblema do que não somos. Nos anos 1920 do século passado, os modernistas brasileiros se perguntaram: 0 que é "ser brasileiro"? E, na impossibilidade de reconhecer-se como tal: Como tornar-se brasileiro? Se a questão moderna brasileira é eminentemente ontológica e epistemológica, é porque interpela diretamente o ser e o devir. Mais do que interpelados, ameaçados de extinção enquanto povo, os Palestinos forjaram na luta uma resposta pela boca de Darwich e de tantos outros.

Tentando responder a essas perguntas, os modernistas brasileiros saíram em busca da "redescoberta" do Brasil e acabaram descobrindo o Outro, isto é, os índios, que constituíam uma das três grandes correntes populacionais da formação do povo brasileiro (com os europeus e os africanos trazidos como escravos); mais ainda: descobriram que, apesar do genocídio inconfessado praticado desde 1500, muitos desses povos ainda sobreviviam no território nacional. Portanto, o Outro não era o de fora, o Outro era o Outro da própria terra, do lugar, presente e, no entanto, sistematicamente ignorado, "ausente". E era esse Outro que fazia o

14 DARWICH, M. Présente absence. Tradução do árabe Farouk Mardam-Bey e Elias Sanbar. Arles: Actes Sud, 2016. p. 80-81. (Col. Mondes arabes). 
brasileiro moderno perceber-se como um "desterrado em sua própria terra", nos dizeres de Sérgio Buarque de Holanda.

Assim, nos anos 1920-1930, ficou claro que, para saber o que é ser brasileiro ou como tornar-se um, seria preciso pôr sobre a mesa o que é ser índio e como os brasileiros lidam, ou melhor, não lidam com isso. No Manifesto Antropófago, Oswald de Andrade formulou a questão de maneira tremenda no seu achado paródico do dilema hamletiano: "Tupy or not tupy, that is the question"15.

Formulado em língua estrangeira, mais propriamente na língua de Shakespeare, o statement não poderia expressar melhor a condição esquizofrênica do brasileiro moderno, pois este se encontra diante de um double bind que, segundo Gregory Bateson ${ }^{16}$, não permite opção e decisão. Com efeito, quanto mais tentamos resolvê-lo, mais afundamos na armadilha. Isso ocorre porque tanto os brasileiros quanto os índios, tanto os selvagens quanto os civilizados não podem ser eles mesmos sem "resolver" sua relação com o Outro, historicamente negada e recalcada. Pois o que dizem os brasileiros para os índios: "Vocês não podem ser brasileiros porque são índios!". E também: "Vocês não podem ser índios porque são brasileiros!". Assim, índios e brasileiros têm o seu devir bloqueado pelo dilema "Tupy or not Tupy...".

Mahamoud Darwich deveria ser ensinado nas nossas escolas, para que as nossas futuras gerações aprendessem o que é a paixão exemplar e irremissível de um povo pelo seu lugar no mundo.

\section{Referências}

BATESON, G. Steps to an Ecology of the Mind: A Revolutionary Approach to Man's Understanding of Himself, 271-278. Chicago: University of Chicago Press, 1972.

15 NUNES, Benedito. Antropofagia ao alcance de todos. In: ANDRADE, Oswald de. Do Pau-Brasil à Antropofagia e às Utopias. Rio de Janeiro: Civilização Brasileira, 1972. p. XXVI. (Obras completas de Oswald de Andrade, v. VI).

16 BATESON, G. Steps to an Ecology of the Mind: A Revolutionary Approach to Man's Understanding of Himself, 271-278. Chicago: University of Chicago Press, 1972. 
DARWICH, M. Présente absence. Tradução do árabe Farouk Mardam-Bey e Elias Sanbar. Arles: Actes Sud, 2016. (Col. Mondes arabes).

DARWICH, M. La Palestine comme métaphore. Tradução do árabe Elias Sanbar; tradução do hebraico Simone Bitton. Arles: Actes Sud, 1997. (Col. Babel).

DARWICH, M. Discours de l'indien rouge. Tradução para o francês de Elias Sandar. Culture et politique arabes, 14 fev. 2010. Disponível em: https://cpa. hypotheses.org/1641. Acesso em: 1 ago. 2020.

DELEUZE, G. Deux régimes de fous: textes et entretiens 1975-1995. Paris: Les Éditions de Minuit, 2003.

MARDAM-BEY, F.; SANBAR, E. Être árabe: Entretiens avec Christofe Kantcheff. Arles: Actes Sud, 2005. (Col. Sindbad).

NUNES, Benedito. Antropofagia ao alcance de todos. In: ANDRADE, Oswald de. Do Pau-Brasil à Antropofagia e às Utopias. Rio de Janeiro: Civilização Brasileira, 1972. (Obras completas de Oswald de Andrade, v. VI).

SMITH, Henry A. Chief Seattle's 1854 Speech. Center for the Study of the Pacific Northwest. Disponível em: https://www.washington.edu/uwired/ outreach/cspn/Website/Classroom\%20Materials/Reading\%20the\%20Region/ Texts\%20by\%20and\%20about\%20Natives/Texts/7.html. Acesso em: 1 ago. 2020. 